\title{
Application of Analytic Hierarchy Process in Selection of an Appropriate Drying Platform for Maize Drying in a Solar Bubble Dryer
}

\author{
Kwashie A. Armah'1, Joseph 0. Akowuah ${ }^{1 *}$, George Obeng-Akrofi², Samuel G. McNeill³ \\ ${ }^{1}$ Department of Agricultural and Biosystems Engineering, Kwame Nkrumah University of Science and Technology, \\ Kumasi, Ghana \\ ${ }^{2}$ Department of Agricultural and Biosystems Engineering, Iowa State University, Ames, IA, USA \\ ${ }^{3}$ Biosystems and Agricultural Engineering, University of Kentucky, Lexington, KY, USA \\ Email: *akowuahjoe@yahoo.co.uk, *joakowuah.soe@knust.edu.gh
}

How to cite this paper: Armah, K.A., Akowuah, J.O., Obeng-Akrofi, G. and McNeill, S.G. (2021) Application of Analytic Hierarchy Process in Selection of an Appropriate Drying Platform for Maize Drying in a Solar Bubble Dryer. Open Journal of Applied Sciences, 11, 157-175.

https://doi.org/10.4236/ojapps.2021.111011

Received: December 11, 2020

Accepted: January 26, 2021

Published: January 29, 2021

Copyright (c) 2021 by author(s) and Scientific Research Publishing Inc. This work is licensed under the Creative Commons Attribution International License (CC BY 4.0).

http://creativecommons.org/licenses/by/4.0/

\begin{abstract}
The solar bubble dryer (SBD) is a convenient and better option to traditional open sun drying commonly practiced by smallholder farmers in Ghana and other developing countries. However, to operate the SBD, one is faced with the challenge of frequent mixing of grains using a rake to enhance uniform drying and prevent over-heating of the top-layer exposed to the sun. Additionally, condensation in the SBD can compromise the quality of grains during drying under humid conditions. In the present study, the Analytical Hierarchy Process (AHP) was used to select an appropriate drying platform, tarpaulin, or elevated drying rack for maize drying in the SBD. Using the AHP, the elevated drying rack was chosen as a suitable platform for drying maize in the SBD. The SBD with the elevated drying racks was used to dry $270 \mathrm{~kg}$ of maize from a moisture content of $18.2 \%$ to $12.6 \%$ (w.w.b) within 6 hours compared to 11 hours for the same quantity of grains dried on the tarpaulin of the SBD to reach an MC of $12.5 \%$ (w.w.b). An average drying rate and moisture extraction rate of $0.93 \% / \mathrm{h}$ and $2.88 \mathrm{~kg} / \mathrm{h}$ were achieved with the elevated drying rack system compared to $0.52 \% / \mathrm{h}$ and $1.60 \mathrm{~kg} / \mathrm{h}$ when drying on the tarpaulin of the SBD. An average temperature of $44.6^{\circ} \mathrm{C}$ recorded in the SBD was $9^{\circ} \mathrm{C}$ more compared to the ambient temperature. The thermal efficiency of the SBD collector was determined as $36.2 \%$. Drying grains with the elevated racks showed advantages of reduced drying time, improved airflow through the drying bed, and prevention of condensation, which occurs when drying on the tarpaulin of the SBD.
\end{abstract}

\section{Keywords}

Solar Bubble Dryer, Analytic Hierarchy Process (AHP), Elevated Drying 
Rack, Maize Drying

\section{Introduction}

Maize is one of the major crops grown in Ghana with a high commercial value. It accounts for $50 \%-60 \%$ of Ghana's total cereal production and represents the country's second-largest crop commodity after cocoa [1]. Maize is used as the main ingredient in livestock feed and processed into many food and industrial products, including starch, sweeteners, corn oil, beverage and industrial alcohol, and fuel ethanol [2].

Maize is mostly harvested at $20 \%$ to $30 \%$ moisture content (wet basis) to avoid the risk of insects, disease, and kernel damage during harvest and also to reduce the growing season where two or more crops are grown in a year. Notwithstanding, rain can force farmers to harvest maize at a high moisture level. Maize harvested with high moisture requires rapid drying for safe storage to prevent germination, mould damage and insect infestation [3]. In Ghana, the safe moisture content for storage of maize grain is $12 \%$ to $13 \%$ (w.b.) [4].

Maize is traditionally dried directly under the open sun by most smallholder maize farmers in rural Ghana. Although this method requires little or no investment, open sun drying is highly dependent on the availability of the sun making the grain susceptible to contamination from foreign materials as well as insects and fungal infestations, which thrive in moist conditions [5]. The practice is also labour intensive, time-consuming, often requiring large open space and long drying time, thereby resulting in non-uniform drying and growth of microorganisms and insect infestation [6].

To address the shortfalls of the traditional open-sun drying, high temperature dryers have been developed to improve the dried produce's quality and shelf-life. However, these drying systems are often centralized and inaccessible to the smallholder farmer due to the high cost of drying and process variability [7]. Moreover, the energy for drying in these conventional mechanical drying systems is supplied from fossil fuel, natural gas or electricity which have become expensive [8] and emit gases that pollute the environment.

Recent studies have focused on solar drying technologies as a cheaper, cleaner and convenient drying system for smallholder farmers [9]. Experimental evaluation on the performance of various solar dryers has shown an improvement. It can ensure quality and extend the shelf-life of the dried produce compared to the traditional open-sun drying method [10].

Different types and modifications of solar dryers are available in various sizes and designs depending on the requirements [10]. The Solar Bubble Dryer (SBD) uses the greenhouse approach to prevent rain from rewetting the crops and shielding it from animals by enclosing it in a transparent bubble that speeds the drying process using the solar energy gained. It is easier to transport, less time to 
install, environmentally friendly, and convenient to dry smaller quantities up to $1000 \mathrm{~kg}$ per batch. It was initially used in Ghana in an initial trial in 2015 to dry grain sorghum, and results were reported by [11]. The result was encouraging, although improvements for enough airflow through the grain bed and mixing for quick and uniform drying to reduce the drying time and increase the dryer's capacity were identified as a key to improve the SBD. This will ensure less temperature variation between grains on the top and bottom layers during drying and is corroborated by [12], who reported that the temperature of grains in the SBD's bottom layer often reaches the dew point temperature.

To ensure better air movement through the grain bed during drying in the SBD, the Analytical Hierarchical Process (AHP) developed by T. L. Saaty (1970) was deployed to select an appropriate drying method during the use of the SBD. The AHP is a decision-making method for relative measurement [13] and is a good tool to analyze and select the best option from different alternatives. It provides an objective approach for ranking decision variables or criteria [14]. As reported by [15], AHP provides a flexible method to provide a simple way to find the relationship between design criteria and alternatives. The analysis can include qualitative and quantitative aspects of the problem. This method has been applied to different fields of study. [16] reported using AHP to select the drying and harvesting process of microalgae systems. It was used for choosing a long-life tomato drying system by [17], while [18] applied it to select a biomass furnace for maize drying. [19] used it in the evaluation and selection of mobile health applications.

In this paper, the AHP model was applied to evaluate and select an appropriate drying process, which involved drying grains on the tarpaulin of the SBD or on an elevated rack incorporated into the SBD to maximize its performance for drying maize. Furthermore, the SBD was evaluated on the drying rate and moisture extraction rate for maize grains dried with the selected preferred drying system.

\section{Materials and Methods}

\subsection{General View of Analytical Hierarchy Process}

The AHP multiple-criteria technique is based on branching complex problems into a hierarchical structure of goal, criteria and alternatives. According to [14] [15] [17], AHP can be explained in four steps:

Step 1-Subdivision of the problem and construction of the hierarchy: the drying method selection process was broken from top to bottom in hierarchical structure as shown in Figure 1. The goal is located at the top of the hierarchy, criteria and sub-criteria put at the lower levels and the drying process alternatives at the bottom of the structure.

Step 2-Pairwise comparison: the factors in the criteria and sub criteria are pairwise compared in terms of importance using Saaty's fundamental scale as shown in Table 1 . Numerical weights were given with their contribution to the 


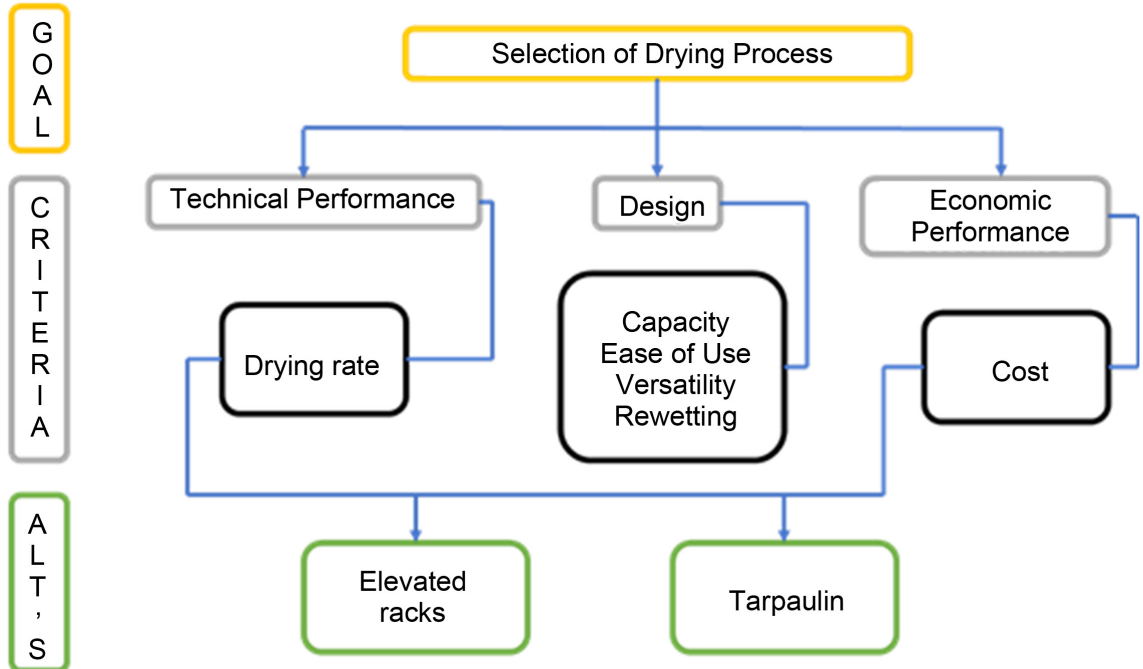

Figure 1. Hierarchical structure of the drying process selection.

Table 1. Saaty's fundamental scale.

\begin{tabular}{|c|c|c|}
\hline Scale & Definition & Explanation \\
\hline 1 & Equally important & $\begin{array}{l}\text { Both elements have equal contribution in the objective } \\
\text { or goal. }\end{array}$ \\
\hline 3 & Moderately important & An element is slightly more important than another. \\
\hline 5 & Strongly important & An element is strongly important than another. \\
\hline 7 & Very strong and proven & $\begin{array}{l}\text { An element is strongly important and is dominant } \\
\text { than another. }\end{array}$ \\
\hline 9 & Extremely important & An element is extremely important than another. \\
\hline $2,4,6,8$ & Inter values & Between the importance of $1,3,5$ and 7. \\
\hline
\end{tabular}

goal in a range of 1 to 9 . The scale contains 5 levels and 4 mid-levels which verbally describes the intensity.

Step 3-Creation of pairwise comparison matrix: after the pairwise comparison, mathematical computation was done to establish relative weight of criteria and was normalized by the vector associated with highest value of the comparison matrix. To check the consistency of the matrix created, consistency ratio (CR) values $(\mathrm{CR} \leq 0.1)$ indicate good decision [17]. The calculation of CR is important and considers one entry over the other in the matrix.

Step 4-Determination of composite weight: the weight of the alternatives was determined by adding the weight of each alternative through the hierarchy down to the lowest level and multiplying the weights along each criterion. The results of this process are a standardized vector of the global weights of the alternatives.

\subsection{Application of AHP to the Study}

In the selection of the appropriate drying process in the SBD, relevant considerations were made to the achievement of the stated goals as narrated in Table 2. 
Table 2. Gives all the criteria considered for selecting the appropriate drying process.

\begin{tabular}{ccl}
\hline Symbol & Name of Criterion & \multicolumn{1}{c}{ Description } \\
\hline C1 & Drying Time & $\begin{array}{l}\text { The time required to dry the maize to safe moisture content. } \\
\text { This is defined as the quantity of grains to be dried. } \\
\text { At the same depth or thickness, can the quantity of the } \\
\text { grains be increased based on the method } \\
\text { without affecting the drying rate. }\end{array}$ \\
C3 & Case of Use & $\begin{array}{l}\text { This defines the ease to set-up the dryer and stocking it as } \\
\text { well as mixing the drying products to attain uniform drying. }\end{array}$ \\
C5 & Cost & $\begin{array}{l}\text { This defines the cost of the drying methods. } \\
\text { Is there any chance for reabsorption of moisture into } \\
\text { the drying product in case of bad weather } \\
\text { condition or during the night? }\end{array}$ \\
C6 & Versatility & $\begin{array}{l}\text { Can the drying method support drying of different product } \\
\text { with ease at the same time? }\end{array}$ \\
\hline
\end{tabular}

Weight were given to the criteria with relative importance with respect to the goal of the study based on studies by [19]. These are the detailed procedure:

Step 1-Problem Identification: The goal of the study was identified in Figure 1 .

Step 2-Establishing the decision-making criteria: The criteria on which the goal was achieved were identified in Table 2 and written in decision criteria matrix $C=\left[C_{j}\right]$, where $j=(1,2,3,4,5,6)$.

Step 3-Establishing a decision-making alternative: the alternatives, out of which the selection was made, were identified and written in alternatives matrix $A=\left[A_{i}\right]$, where $i=1$ and 2 .

Step 4-Determination of relative weight of criteria by pairwise comparison: The relative importance of the criteria, $c=\left[c_{i j}\right]$ with respect to the goal were determined by performing a pairwise comparison. The relative importance of each attribute was determined through literature reviews and experimentations on the effect on each attribute have on the selection of the appropriate drying process within the SBD. The weight given to each criterion was based on the $\mathrm{T}$. L. Saaty fundamental scale.

Step 5-Developing the vector weight: In a pairwise comparison matrix $A$, a vector $W=\left[W_{1}, W_{2}, \cdots, W_{m}\right]$ which indicate the weight given to each criterion. To determine the weight:

1) At each of the $A$ 's column, every entry in column $i$ of $A$ was divided by the sum of the entries in column $i$. this yields a new matrix, $A_{\text {norm }}$. However, the sum of each column in the $A_{\text {norm }}$ matrix must be 1.

2) The $W_{i}$ was estimated as the entries in row $i$ of $A_{\text {norm }}$.

Step 6-Determining the consistency factor: In other to avoid any bias by the researcher or decision maker in allocation of weights, the pairwise comparison matrix is subjected to consistency check. The consistency factor was determined using the process below: 
1) Determine the maximum Eigen values of the pairwise matrix

$$
\lambda_{\max }=\frac{1}{m} \sum_{i=1}^{n} \frac{i^{\text {th }} \text { entry in } A W^{\mathrm{T}}}{i^{\text {th }} \text { entry in } W^{\mathrm{T}}}
$$

2) Determine the consistency index, CI

$$
\mathrm{CI}=\frac{\lambda_{\max }}{m-1}
$$

3) Determining the consistency factor: CI was compared to the Random Index, RI for the appropriate value $\mathrm{m}$, used in decision making. For acceptance limit for $(\mathrm{CI} / \mathrm{RI})$ is 0.1 or less. If the value exceeds 0.1 , then there are more inconsistencies and the pairwise comparison should be carried out again to be more consistent.

Step 7-Determining the relative weights of the alternatives based on criteria. Steps 4 and 5 were followed to develop square matrices of size $i$ (equal to the number of alternatives). The number of matrices developed is equal to the number of criteria considered in the study.

Step 8-Filling in the performance matrix, where the performance of the alternatives was identified for each criterion, and the data were written in the performance matrix $P=\left[P_{i j}\right]$.

Step 9-Finally, the total weight for the priority of each alternative was determined by multiplying the weight of each alternative related to each criterion with the weight of each criterion, and then calculated their sum, i.e., $P \times W^{T}$.

Therefore, the best alternative is the one with the highest value after the sum of multiplication between the weight of each alternative and the weight of each criterion.

\subsection{Experimental Set-Up}

\section{Description and Mode of Operation of the SBD}

As shown in Figure 2, the Solar Bubble Dryer ${ }^{\mathrm{Tn}}$ (GrainPro, Zambales, Philippines) is made of a UV-stabilized transparent polyethylene film (upper half) and connected by a zipper to a reinforced black polyvinyl chloride (PVC) film (lower half). A heavy-duty zipper is aligned and stitched along the edges of both plastic films. The SBD dimension is $25 \mathrm{~m} \times 2 \mathrm{~m} \times 1 \mathrm{~m}$ with a capacity of $1000 \mathrm{~kg}$ of grains depending on the type of grain or products to be dried. The tunnel does

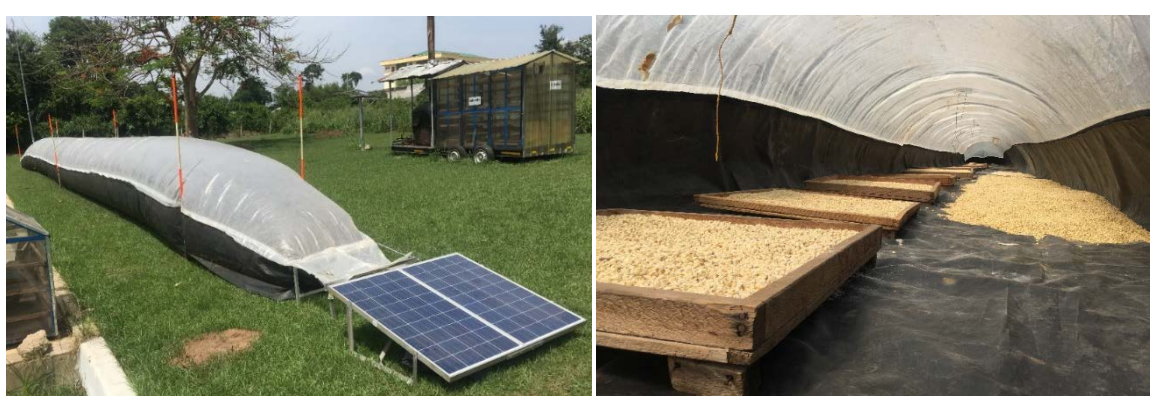

Figure 2. Set-up of drying experiment with elevated racks and maize on tarpaulin of SBD. 
not require a support structure and stabilizes adequately by air pressure from inflation. Two $12 \mathrm{~V}$ DC axial flow fans blow air into the tunnel exhausted through two vents on the opposite side. A two $100 \mathrm{~W}$ solar panel charges a $70 \mathrm{AH}$ battery that provides power to the fans.

The air from the fan or the ventilators keeps the dryer inflated. The air in the tunnel is heated by the transparent cover, which traps the dryer's solar energy. Heat continuously build-up as the intensity of the solar radiation keeps increasing. The heated air has low relative humidity and can evaporate moisture from the drying materials. The moist air moves out of the dryer through the exit with the help of the fan. Mixing is usually done using a rake. The rake is inserted through the zip opening and moved along the drying tunnel.

\subsection{Materials and Instrumentation}

The list of materials and instruments used during the experiment is presented in Table 3.

\subsection{Experimental Set-Up and Data Logging Points}

The drying experiment using the SBD (Figure 2) was set-up at the Department of Agricultural and Biosystems Engineering, KNUST, Kumasi, Ghana. The dryer was set-up on October 01, 2019 to October 03, 2019 to record experimental data.

A total of $540 \mathrm{~kg}$ of a local white maize variety known as Omankwa was harvested from a local farmers' field and used to evaluate the dryer's performance. The initial moisture content was determined using a Dickey John mini GAC plus moisture Analyser.

The SBD was divided into six sections, as shown in Figure 3, and labeled sequentially (S1 - S6). The distance between the sections was $4 \mathrm{~m}$ apart. The dryer was also laterally divided into two halves with 18 elevated drying racks, each containing $15 \mathrm{~kg}$ of maize placed on one side (Figure 3). In contrast, the opposite side was used to dry a total of $270 \mathrm{~kg}$ of maize grains with 6 - $45 \mathrm{~kg}$ piles placed on the SBD floor directly opposite the dying racks (Figure 2 and Figure 3).

Table 3. Materials and Instruments used for the experiment.

\begin{tabular}{cccc}
\hline SN & $\begin{array}{c}\text { Material/ } \\
\text { Instrument }\end{array}$ & Description & Use \\
\hline 1 & Moisture meter & Dickey John mini GAC plus & $\begin{array}{c}\text { Moisture content of } \\
\text { maize grain } \\
2\end{array}$ \\
3 & Weighing scale & Constant 14192-135E & Used for the study \\
4 & Anemometer & Kestrel 4200 & Weight of maize \\
5 & Tinytag data logger & Tinytag Plus 2-TGP-4017 & $\begin{array}{c}\text { Airflow rate } \\
\text { Temperature and relative } \\
\text { humidity in the dryer }\end{array}$ \\
& Pyranometer & Amprobe SOLAR-100 & Solar radiation \\
\hline
\end{tabular}




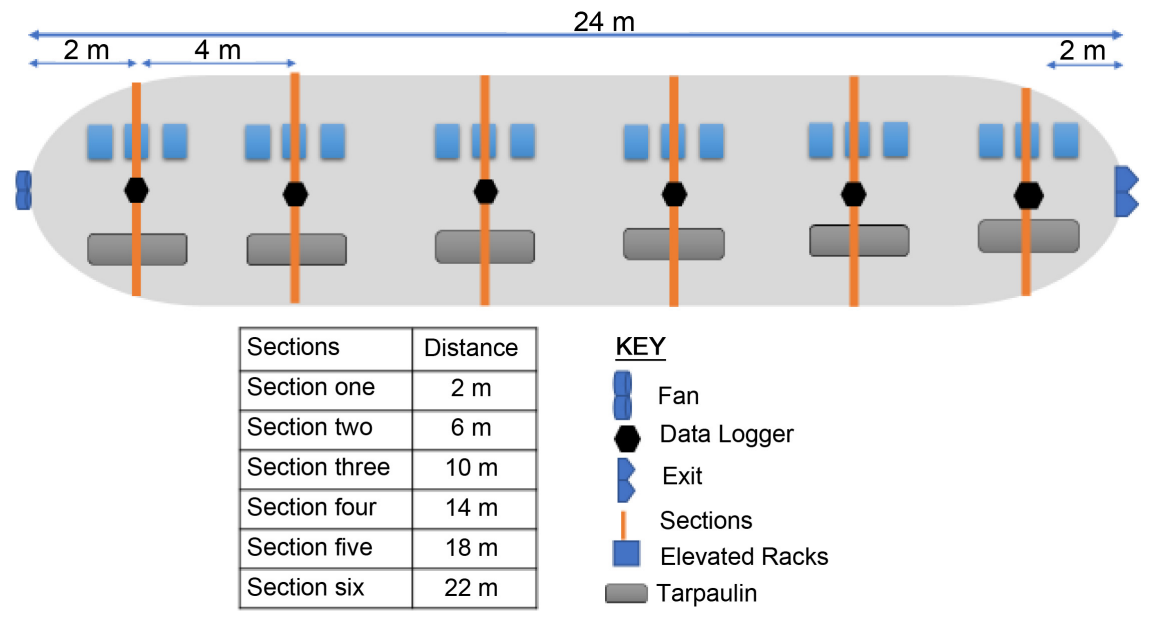

Figure 3. Data logging points, position of elevated racks and grains on tarpaulin in SBD.

The depth of maize grain in the drying racks and on the tarpaulin was the same at $0.04 \mathrm{~m}$. Three racks representing replicate drying racks were placed opposite to grains on the floor at each data logging position, as shown in Figure 3. The average moisture content of the three racks represented the moisture content at the section. Grains on the tarpaulin were sampled from different points before the moisture content was determined using the Dickey John mini GAC plus moisture Analyser. Data loggers (TinyTag Plus 2-TGP-4017) were placed at each drying section to measure the temperature and relative humidity. The loggers were also used to record the ambient temperature and relative humidity. The moisture content of maize grains on the tarpaulin was measured at hourly intervals using the moisture Analyser. The weight of maize grains in the drying racks was monitored hourly by weighing using an electronic weighing scale (Constant 14192-135E). The process was repeated until the final moisture content of grains was achieved.

\subsection{Dryer Performance}

The performance assessment of the solar bubble dryer was monitored using dryer performance indices such as; thermal efficiency of solar collector, drying efficiency, drying rate and moisture extraction rate.

\subsubsection{Thermal Efficiency of the Solar Collector}

The thermal efficiency of the solar collector was calculated using Equation (3) [20]

$$
\eta_{c}=\frac{C_{p} m_{a}(\Delta T)}{A_{s} I}
$$

\subsubsection{Drying Rate}

Drying rate was determined using Equation (4)

$$
\mathrm{DR}=\frac{m_{i}-m_{f}}{t}
$$




\subsubsection{Moisture Extraction Rate MER}

The moisture extraction rate was determined using Equation (5)

$$
\text { MER }=w_{i} \times \frac{\left(\frac{m_{i}-m_{f}}{100-m_{f}}\right)}{t}
$$

\subsubsection{Moisture Content Determination}

The initial moisture content of the maize sample was determined using the oven method. It was determined on wet basis as presented in Equation (6) where $M_{i}$ is the initial moisture content, $W_{i}$ is the initial weight of maize and $W_{f}$ is the final weight of maize.

$$
M_{i}=\frac{W_{i}-W_{f}}{W_{i}} \times 100
$$

The instantaneous moisture content, $M_{t}$ at any given time $(t)$ on wet basis was determined using Equation (7) as presented by [20]; where $W_{t}$ is the weight of grain at time $(t)$.

$$
M_{t}=\left[\frac{\left(M_{i}+1\right) W_{t}}{W_{i}}-1\right]
$$

\subsubsection{Airflow Pattern and Velocity in the Solar Bubble Dryer}

The velocity of air along the length of the SBD from the entry, midsection and exit was measured with an anemometer. This was done by placing the anemometer against the direction of flow and the values record. This was replicated three times at positions along the length of the SBD and the average values recorded to represent the air velocity at the different sections. The air velocity values at the various sections was modelled using MATLAB (Version 8.5 R2015a) Computational Fluid Dynamics (CFD) Toolbox (CFDTool) to model and simulate the airflow pattern and location flow intensity in the SBD. The Tinytag data logger was used to log the temperature condition of the air in the SBD.

\section{Results and Discussions}

\subsection{Selection of Appropriate Drying Process}

This section of the study focuses on the results from the application of the analytical hierarchical process, AHP to select the preferred drying alternative drying process to dry maize in the SBD which was then used for the experiment. The preferred drying process was applied to dry maize in the SBD based on its ability to dry grains faster and provide uniform drying with possibility of increasing the capacity of the dryer for acceptance and adoption by smallholder farmers in Ghana.

\section{Application of AHP}

Table 4 presents the pairwise comparison between criteria using the judgmental scale of Saaty (1980). 
Table 4. Pairwise comparison between criteria.

\begin{tabular}{ccccccc}
\hline Criteria & $\mathrm{C} 1$ & $\mathrm{C} 2$ & $\mathrm{C} 3$ & $\mathrm{C} 4$ & $\mathrm{C} 5$ & $\mathrm{C} 6$ \\
\hline $\mathrm{C} 1$ & 1 & 2 & 3 & 5 & 7 & 9 \\
$\mathrm{C} 2$ & 0.5 & 1 & 3 & 5 & 7 & 9 \\
$\mathrm{C} 3$ & 0.33 & 0.33 & 1 & 2 & 4 & 7 \\
$\mathrm{C} 4$ & 0.2 & 0.2 & 0.5 & 1 & 3 & 5 \\
$\mathrm{C} 5$ & 0.14 & 0.14 & 0.25 & 0.33 & 1 & 3 \\
$\mathrm{C} 6$ & 0.11 & 0.11 & 0.14 & 0.2 & 0.33 & 1
\end{tabular}

C1 Drying time; C2 Capacity; C3 Ease of use; C4 Cost; C5 Rewetting; C6 Versatility.

The weight of each criterion was based on literature review, technical knowledge and general engineering principles with the goal in mind. Some of these principles have been applied by other researchers in other fields of study. In the selection of drying process, the drying rate is more important to be considered than the ease of use of the process. This makes a value of 3 to be given to $\mathrm{C} 2$ in comparing $\mathrm{C} 2$ and $\mathrm{C} 3$. In filling the matrix, if $\mathrm{C} 2$ is 3 times more important than $\mathrm{C} 3$ then $\mathrm{C} 3$ is $1 / 3$ times more important than $\mathrm{C} 2$. Also, comparison of a matrix by itself, the judgmental scale is 1 . This accounts for the reason 1 is on the matrix diagonal [15].

The decision criteria matrix was normalized and transformed into weights to know the extent to which each criterion has on the selection of a better drying process. This was achieved with step 5 as presented in chapter 3. Table 5 shows the normalized form of the decision criteria matrix.

The average value of each row in the $A_{\text {norm }}$ matrix in Table 5 represents each criterion's weights for the selection process. Figure 4 shows that, in selecting an appropriate drying method, the drying rate is the most important since it has a relative weight of 0.38 out of 1 . This is followed by capacity, ease of use, cost, rewetting, and versatility with the relative weight of $0.30,0.14,0.09,0.05$ and 0.03 , respectively.

In selecting an appropriate drying process in the solar bubble dryer, the drying time is an important factor that must be considered. An effective drying process should reduce the drying time because prolonged drying poses a high risk for spoilage for most agricultural products [12]. The process should allow heated air to move through the drying product by increasing the drying products' surface area. That is, increase product contact with heated air during drying [21]. An increase in the product surface area increases the moisture extraction rate and reduces the drying time [22]. [12] reported that the best drying process should allow heated air to move through the drying products other than moving over the surface or at the upper part of the drying product which does not yield uniform drying.

Also, ease of use, cost and rewetting are important criteria for selecting a drying process in the SBD. Farmers in Ghana will prefer a method that is cost-effective and less tedious. Less contact with drying material will reduce 
Table 5. Normalized form of decision criteria matrix.

\begin{tabular}{ccccccc}
\hline Criteria & $\mathrm{C} 1$ & $\mathrm{C} 2$ & $\mathrm{C} 3$ & $\mathrm{C} 4$ & $\mathrm{C} 5$ & $\mathrm{C} 6$ \\
\hline $\mathrm{C} 1$ & 0.44 & 0.53 & 0.38 & 0.37 & 0.31 & 0.26 \\
$\mathrm{C} 2$ & 0.22 & 0.26 & 0.38 & 0.37 & 0.31 & 0.26 \\
$\mathrm{C} 3$ & 0.15 & 0.09 & 0.13 & 0.15 & 0.18 & 0.21 \\
$\mathrm{C} 4$ & 0.09 & 0.05 & 0.06 & 0.07 & 0.13 & 0.15 \\
$\mathrm{C} 5$ & 0.06 & 0.04 & 0.03 & 0.02 & 0.04 & 0.09 \\
C6 & 0.05 & 0.03 & 0.02 & 0.01 & 0.01 & 0.03 \\
Total & 1 & 1 & 1 & 1 & 1 & 1 \\
\hline
\end{tabular}

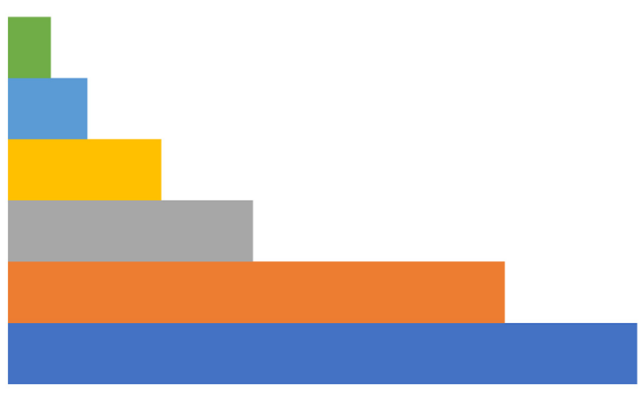

$$
\begin{aligned}
& \square \text { Versatility } \\
& \square \text { Rewetting } \\
& \square \text { Cost } \\
& \square \text { Ease of Use } \\
& \square \text { Capacity } \\
& \square \text { Drying Time }
\end{aligned}
$$

Figure 4. Relative weights of criteria.

product damage (stress cracks) in some agricultural products. A drying process that will reduce the drying time, thereby reducing the incidence of leaving products on field at night, causes some rewetting levels [12].

The consistency factor of the decision criteria matrix was further determined to assess the consistency of the developed decision criteria matrix. With 6 criteria considered, a value of 1.24 was selected as the random index, RI [23]. The maximum Eigen-value for the decision criteria matrix was calculated to be 6.41 using Equation (1), with the consistency index calculated as 0.082 . Finally, the consistency ratio of 0.066 was determined. This means the decision criteria matrix used for the study was consistent. The results obtained are in agreement with studies by other researchers who applied AHP to achieve various goals [14] [15] [17].

To generate the weight for the drying process alternatives, the same process for developing decision criteria matrix was performed. The relative weight between the drying process alternatives were normalized according to each of the criterion in order to get the performance matrix of the two drying process alternatives in relation to the 6 decision criteria.

The performance of each alternative according to all criteria considered in the study is presented in Table 6. It was not difficult using AHP to make a judgmental decision in this study based on the criteria. However, in the early stages of the study, it was shown that certain criterion influences the selection of an 
Table 6. Performance of both alternatives to the 6 criteria.

\begin{tabular}{ccc}
\hline Criteria & Alt 1 & Alt 2 \\
\hline Drying time & 0.87 & 0.13 \\
Capacity & 0.75 & 0.25 \\
Ease of use & 0.75 & 0.25 \\
Cost & 0.17 & 0.83 \\
Rewetting & 0.87 & 0.13 \\
Versatility & 0.75 & 0.25 \\
\hline
\end{tabular}

Alternative 1, drying on elevated racks; Alternative 2, drying on tarpaulin.

appropriate drying process over the other. Therefore, the product of the performance matrix (Table 6) and relative weight of criteria (Figure 4) produced a vector that gives the priority value (on a scale of 0 to 1 ) from which the better alternative was selected as shown in Figure 5.

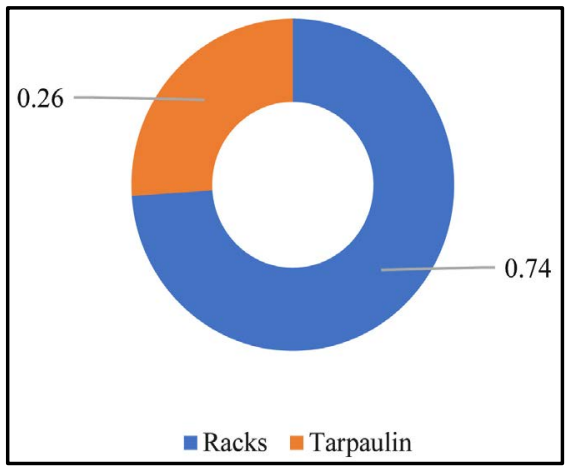

Figure 5. Global priority values of each alternative.

As shown in Figure 5, drying on elevated racks (Alternative 1) was selected as the preferred alternative for drying grains in the SBD. It had the highest priority value of 0.74 compared to 0.26 for drying on the SBD tarpaulin.

\subsection{Performance Evaluation of Solar Bubble Dryer with Elevated Drying Racks}

\subsubsection{Solar Radiation and Temperature Variation}

The solar radiation, ambient temperature, and temperature in the SBD are shown in Figure 6. Due to rains on the day of the set-up, the drying experiment had to be carried out for three days. This resulted in solar intensity variations with a maximum of $1172 \mathrm{~W} / \mathrm{m}^{2}$ and a minimum of $680 \mathrm{~W} / \mathrm{m}^{2}$ recorded during the 3-day drying process.

The ambient temperature varied between $31.8^{\circ} \mathrm{C}$ and $38.0^{\circ} \mathrm{C}$ for the first day of drying, $33.9^{\circ} \mathrm{C}$ and $36.1^{\circ} \mathrm{C}$ for the second day and $35.4^{\circ} \mathrm{C}$ and $38.7^{\circ} \mathrm{C}$ for the third day. During the 3-day drying period, the ambient temperatures recorded were lower than the air temperature in the SBD (see Figure 6). This was due to weather overcast during the days the drying experiment took place. The mini- 
mum and maximum temperatures recorded within the SBD were between $40^{\circ} \mathrm{C}$ and $48.2^{\circ} \mathrm{C}$ for the first day, $40.7^{\circ} \mathrm{C}$ and $49.7^{\circ} \mathrm{C}$ for the second day and $45.1^{\circ} \mathrm{C}$ and $47.4^{\circ} \mathrm{C}$ for the third day. The overall average dryer temperature recorded during the drying period was $44.6^{\circ} \mathrm{C}$ compared to the ambient temperature of $36.2^{\circ} \mathrm{C}$. Temperature variations, as shown in Figure 7 were observed along the tunnel of the SBD. The average temperatures recorded from section one to section six were $38.6^{\circ} \mathrm{C}, 42.8^{\circ} \mathrm{C}, 45.7^{\circ} \mathrm{C}, 44.9^{\circ} \mathrm{C}, 47.1^{\circ} \mathrm{C}$, and $47.7^{\circ} \mathrm{C}$, respectively. This shows a gradual temperature rise from the inlet (section one) through the tunnel's mid-section up to the exit point. This can be attributed to the closeness of section one to the inlet of the dryer, where two suction fans are positions to force ambient air into the dryer.

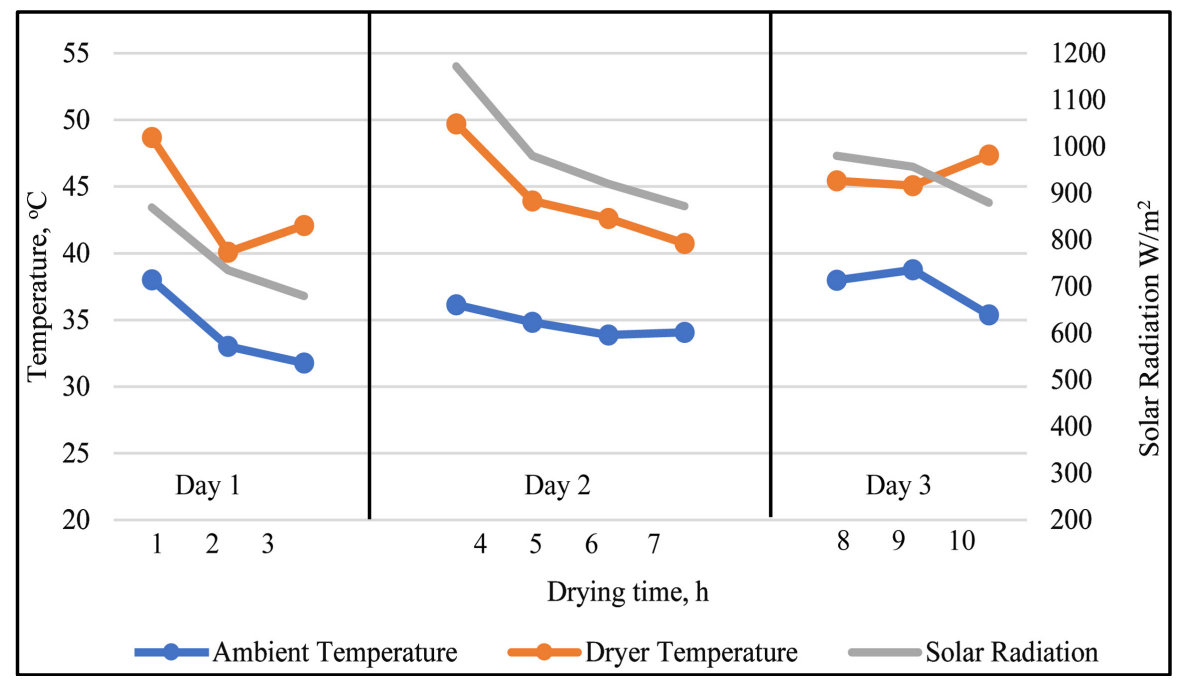

Figure 6. Average ambient temperature, dryer temperature and solar radiation variation during the drying periods.

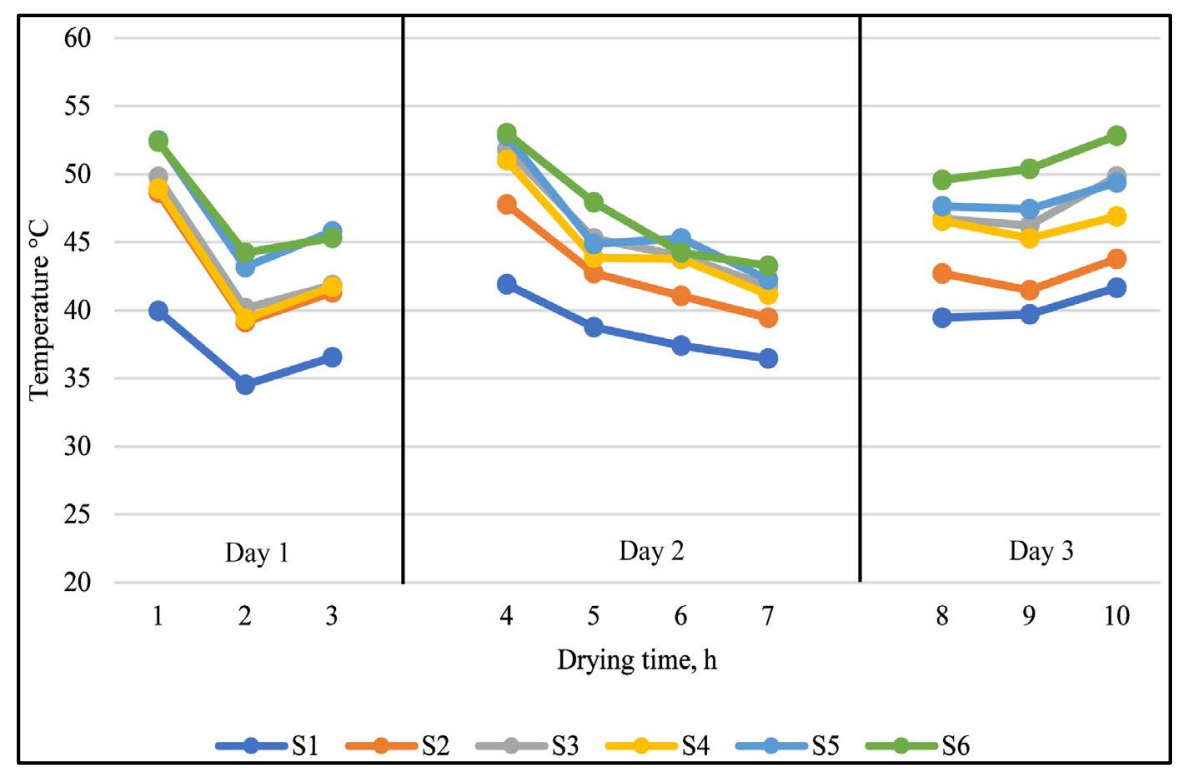

Figure 7. Temperature variation at each section. 
The volume of air entering the inlet tends to damp the heat in the air, thereby reducing the air temperature at the inlet of the dryer. Similar observations were made by [12] when the solar bubble dryer was used to dry paddy rice. Temperature rise in the SBD depends on the amount of solar radiation absorbed by the solar collector, which, according to [24], is the strongest determinant of heat build-up in the bubble dryer. Overall, the thermal efficiency of the SBD collector was determined as $36.2 \%$.

\subsubsection{Airflow Pattern in the SBD}

The pattern of air distribution in the SBD is presented in Figure 8. Air velocity of $5.8 \mathrm{~m} / \mathrm{s}$ was measured at the inlet where an axial fan is position to supply air into the SBD. The entry velocity of air from the fan was measured at full capacity of the battery that fans run on. The battery power is sustained by a solar PV system attached to the SBD. The airflow rate at Section one and two was recorded as $2.2 \mathrm{~m} / \mathrm{s}$ and $0.4 \mathrm{~m} / \mathrm{s}$, respectively. The airflow in the mid-section of the tunnel dryer was sparsely distributed along the edges of the tunnel resulting in no significant value recorded. At the exit, the airflow increased to $3.6 \mathrm{~m} / \mathrm{s}$. This implies that high turbulence was visible at the preheating area before the entry point and at the drying tunnel exit. However, no flow was recorded in the midsection due to the exposed surface area of the mid-section to volume and airflow. The shape of the dryer contributed to the variations in the airflow along the length of the SBD. The inlet and exit sections of the dryer are narrower than the mid-section. This increased the air velocity at the inlet and exit sections compared to the midsections. Additionally, the high temperature recorded in the mid-section contributed to the air getting lighter at the mid-section and by buoyancy effect rising to flow along the edge of the tunnel until it becomes heavier towards the exit as it absorbs more moisture from the grains closer to the exit point of the dryer. The analysis of temperature and airflow pattern in the tunnel had a corresponding relationship with the moisture loss from grains along the length of the tunnel. Grains dried at the mid-section of the dryer recorded the highest moisture loss, followed by grains dried close to the entry and exit sections of the SBD.

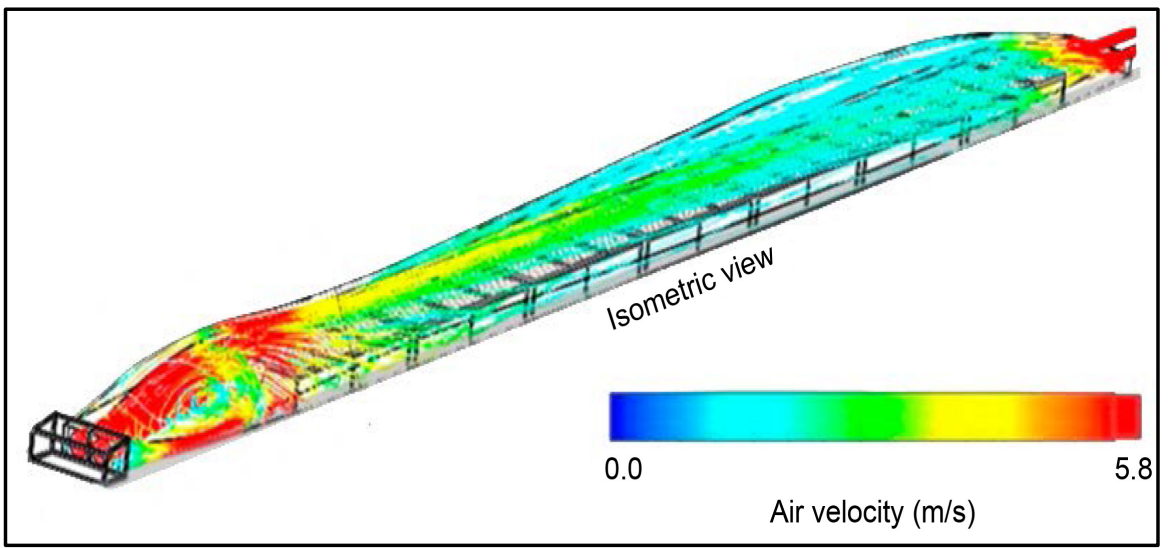

Figure 8. Airflow distribution in the SBD. 


\subsection{Comparison between Moisture Variation Using Elevated Racks and Drying on Tarpaulin}

Maize grains dried on the elevated drying racks were compared to grains dried on the SBD floor/tarpaulin. It was observed (Figure 9) that drying on the tarpaulin took longer than drying with the racks. After 6 hours of drying, the final average moisture content of grains dried using the elevated drying racks reached $12.6 \%$. However, it took 11 hours for grains dried on the floor/tarpaulin to reach the same final average moisture content of $12.5 \%$. This suggests a potential capacity increase for the SBD when elevated drying racks are incorporated for drying maize grains. The shorter drying time achieved with the elevated drying racks is due to the air movement over and under the bed of grains on the racks as corroborated by [25]. However, as reported by [12], for grains on the tarpaulin, the air moves over the surface of the grains and increases the grain temperature at the top layer compared to the bottom layer. This led to a creation of different drying fronts thereby increasing the drying time for grains dried on the tarpaulin of the SBD. Based on the moisture loss over the drying period using the elevated racks and tarpaulin, it was determined that, the faster drying process was recorded with the elevated drying racks. This resulted in an average drying rate and moisture extraction rate of $0.93 \% / \mathrm{h}$ and $2.88 \mathrm{~kg} / \mathrm{h}$ compared to $0.62 \% / \mathrm{h}$ and $1.95 \mathrm{~kg} / \mathrm{h}$ for grains dried on the tarpaulin of the SBD.

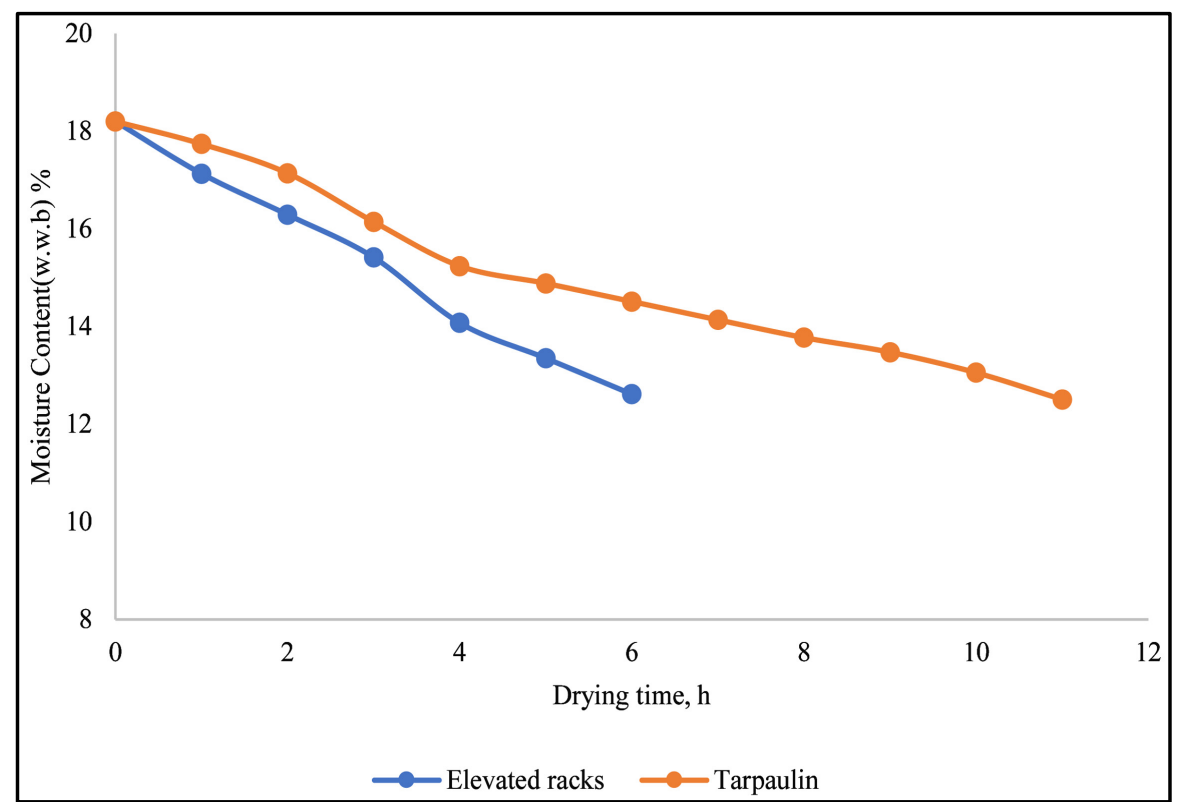

Figure 9. Moisture variation vrs. time for grains dried on elevated racks and tarpaulin of.

\subsection{Effect of SBD Length on Moisture Variation with Time}

To assess the SBD length on moisture loss, maize grains samples were collected from different positions along the length of the SBD for moisture content analysis. There were variations in the moisture content of grains sampled from different positions along the length of the SBD during the drying process. As shown 
in Figure 10, grain moisture content reduced with time, and drying occurred in the falling rate period. After 6 hours of drying, the moisture content of grains reduced from $18.2 \%$ (w.b) to a final average of $12.2 \%$ for grains sampled at $2 \mathrm{~m}$ (section one); $12.7 \%$ for grains at $6 \mathrm{~m}$ (Section 2 ) and $11.9 \%, 13.0 \%, 12.8 \%$, and $13.1 \%$ for grains sampled at $10 \mathrm{~m}$ (Section 3), $14 \mathrm{~m}$ (Section 4), $18 \mathrm{~m}$ (Section 5) and $22 \mathrm{~m}$ (Section 6), respectively, from the entry point of the SBD. Grains dried at the mid-section of the dryer recorded the highest moisture loss, followed by grains dried close to the entry and exit sections of the SBD. According to [12], the drying air temperature varies at different sections along the length of the tunnel of the SBD. This could have contributed to the variation in moisture loss from the grains. This is corroborated by [26], who reported that, as air moves toward the exit, moisture is lost from the grains to the drying air, which increases the moisture in the drying air and reduces its temperature, thereby reducing the air potential to absorb moisture from grains towards the exit of the SBD.

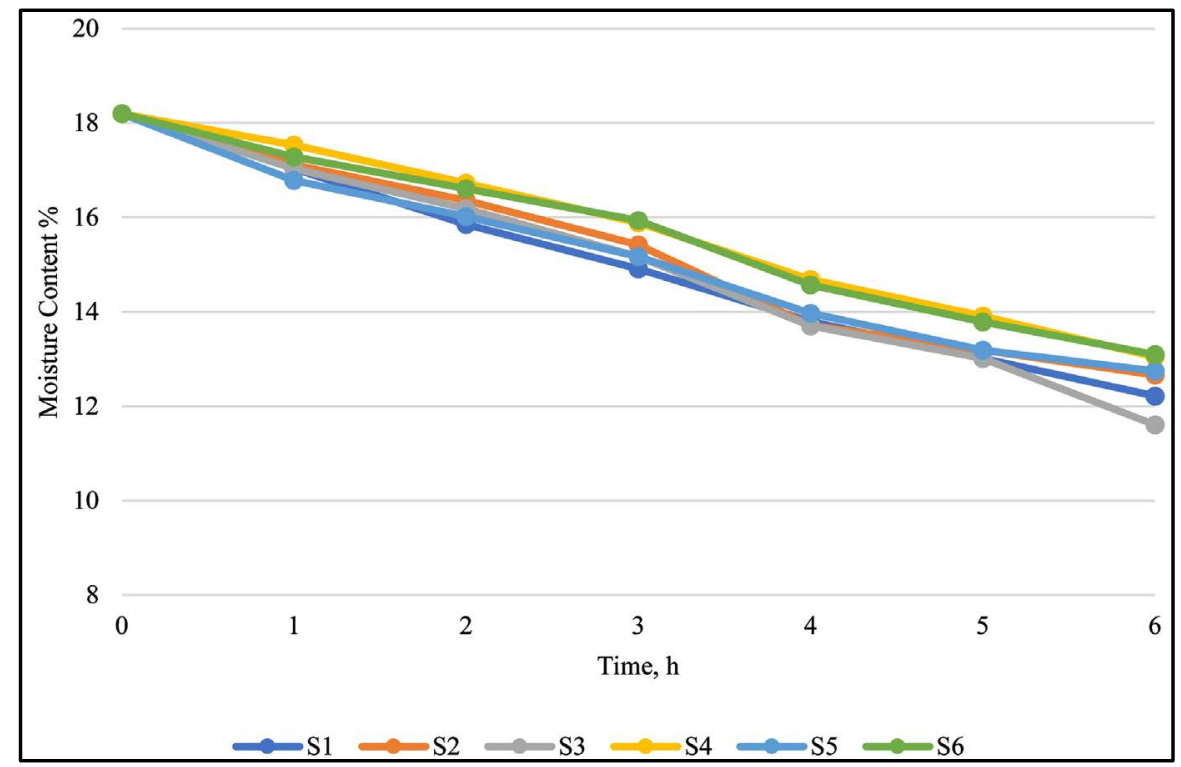

Figure 10. Average moisture content of grains on the elevated racks at various sections along the length of the SBD.

When grains at different moisture content are mixed, the grains tend to attain an equilibrium moisture content that represents the average moisture content. The overall average moisture content of $12.6 \%$ (w.b) after 6 hours of drying recorded for grains dried on the elevated racks falls within the recommended moisture content of $12 \%$ - $13 \%$ for maize grains' safe storage. According to [9], drying maize grains harvested at high moisture to a safe moisture content of about $12 \%$ to $13 \%$ will ensure storage stability.

\section{Conclusions}

The application of the AHP model showed that, drying of maize grains using elevated drying racks in the SBD was a better option than drying on the tarpau- 
lin of the SBD. In the experimental study to evaluate the SBD's performance with the elevated racks, $270 \mathrm{~kg}$ of maize at an initial moisture content of $18.2 \%$ (w.b) was dried using the elevated racks to a final moisture content of $12.6 \%$ within a period of $6 \mathrm{~h}$. However, it took $11 \mathrm{~h}$ for grains dried on the tarpaulin to reach a final moisture content of $12.5 \%$. This resulted in an average drying rate and moisture extraction rate of $0.93 \% / \mathrm{h}$ and $2.88 \mathrm{~kg} / \mathrm{h}$ compared to $0.52 \% / \mathrm{h}$ and $1.60 \mathrm{~kg} / \mathrm{h}$ for grains dried on the tarpaulin of the SBD. Generally, drying on the elevated racks reduced drying time by 5 hours for the same quantity of grains dried on the SBD tarpaulin. The average temperature recorded in the SBD $\left(44.6^{\circ} \mathrm{C}\right)$, was $9^{\circ} \mathrm{C}$ more than the ambient temperature resulting in a thermal efficiency of $36.2 \%$ determined for the SBD collector. The use of the elevated racks can increase the capacity of the SBD and eliminate rewetting or the occurrence of condensation of grains dried on the tarpaulin during drying under humid weather conditions.

The SBD provides opportunity for smallholder farmers to dry their grains in a better hygienic environment compared to the traditional open-sun drying approach. However, to sustain drying in the SBD during poor weather conditions, an external energy source is recommended to provide the needed hot air required for drying.

\section{Acknowledgements}

The authors express sincere gratitude to the Feed the Future Innovation Lab for the Reduction of Post-harvest Loss at Kansas State University

(https://www.k-state.edu/phl/) for providing the solar bubble dryer which was key to the success of this study.

\section{Conflicts of Interest}

The authors declare no conflicts of interest regarding the publication of this paper.

\section{References}

[1] Musah, A.B., Bonsu, O.Y. and Seini, W. (2014) Market Participation of Smallholder Maize Farmers in the Upper West Region of Ghana. African Journal of Agricultural Research, 9, 2427-2435. https://doi.org/10.5897/AJAR2014.8545

[2] Choudhary, R. (2013) Microwave Drying Kinetics and Quality Characteristics of Corn. International Journal of Agricultural and Biological Engineering, 6, 90-99.

[3] Sadaka, S., Ph, D., Vandevender, K. and Ph, D. (n.d.) On Farm Grain Drying Methods. Division of Agriculture Research and Extension, University of Arkansas, Fayetteville, FSA1072.

[4] Wang, Z., Wang, Z., Sun, J., Liao, X., Chen, F. and Zhao, G. (2007) Mathematical Modeling on Hot Air Drying of Thin Layer Apple Pomace. Food Research International, 40, 39-46. https://doi.org/10.1016/j.foodres.2006.07.017

[5] Kumar, A., Kumar, V., Khan, K. and Kumar, A. (2017) Experimental Investigation on Drying of Mint Leaves (M. pulegium) in Solar Tunnel Dryer. International Journal of Pure \& Applied Bioscience, 5, 682-689. 
https://doi.org/10.18782/2320-7051.2498

[6] Kumar, Y., Tiwari, S. and Kumar, Y. (2018) Review on Heat Convection Solar Drying in Dryer. International Journal of Pure \& Applied Bioscience, 6, 1323-1330. https://doi.org/10.18782/2320-7051.6457

[7] Tiwari, A. (2016) A Review on Solar Drying of Agricultural Produce. Journal of Food Processing \& Technology, 7, 623. https://doi.org/10.4172/2157-7110.1000623

[8] Lingayat, A., Chandramohan, V.P. and Raju, V.R.K. (2017) Design, Development and Performance of Indirect Type Solar Dryer for Banana Drying. Energy Procedia, 109, 409-416. https://doi.org/10.1016/j.egypro.2017.03.041

[9] Akowuah, J.O., Maier, D., Opit, G., McNeill, S., Amstrong, P., Campabadal, C. and Obeng-Akrofi, G. (2018) Drying Temperature Effect on Kernel Damage and Viability of Maize Dried in a Solar Biomass Hybrid Dryer. Open Journal of Applied Science, 8, 506-517. https://doi.org/10.4236/ojapps.2018.811041

[10] Kumar, M., Sansaniwal, S.K. and Khatak, P. (2016) Progress in Solar Dryers for Drying Various Commodities. Renewable and Sustainable Energy Reviews, 55, 346-360. https://doi.org/10.1016/j.rser.2015.10.158

[11] McNeill, S., Armstrong, P., Opit, G., Osekre, E., Manu, N., Danso, J., Addo, I., Sanghi, A., Adu-Gyamfi, K. and Nsiah, E. (2015) Assessment of Grain Moisture Measurements and Solar Dryers in Ghana. 1st International Congress on Postharvest Loss Prevention, Rome, 4-7 October 2015.

[12] Salvatierra-rojas, A., Nagle, M., Gummert, M., Bruin, T. and Müller, J. (2017) Development of an Inflatable Solar Dryer for Improved Postharvest Handling of Paddy Rice in Humid Climates. International Journal of Agricultural and Biological Engineering, 10, 269-282.

[13] Brunelli, M. (2015) Introduction to the Analytic Hierarchy Process. SpringerBrriefs in Operations Research. Springer, Berlin, 83.

https://doi.org/10.1007/978-3-319-12502-2

[14] Wolnowska, A.E. and Konicki, W. (2019) Multi-Criterial Analysis of Oversize Cargo Transport through the City, Using the AHP Method. Transportation Research Procedia, 39, 614-623. https://doi.org/10.1016/j.trpro.2019.06.063

[15] Atanasova-pacemska, T.P., Lapevski, M. and Timovski, R. (2014) Analytical Hierarchical Process (AHP) Method Application in the Process of Selection and Evaluation. International Scientific Conference, Gabrovo, 21-22 November 2014, 373-380.

[16] Tan, J., Low K.Y., Sulaiman, N.M.N., Tan, R.R. and Promentilla, M.A.B. (2015) Fuzzy Analytical Hierarchy Process (AHP) for Multi-Criteria Selection in Drying and Harvesting Process of Microalgae System. Chemical Engineering Transactions, $45,829-834$

[17] Jorge, A., Kubaski, E.T., Colmenero, J.C., Sequinel, T., Sequinel, R. and Tebcherani, S.M. (2015) Analytic Hierarchy Process Applied to the Choice of a Long-Life Tomato (Lycopersicon esculentum Mill) Drying System. Drying Technology, 33, 1180-1187. https://doi.org/10.1080/07373937.2015.1020160

[18] Obeng-Akrofi, G., Akowuah, J.O., Addo, A. and Maier, D. (2019) Techno-Economic Analysis of a Crossflow Column Dryer for Maize Drying in Ghana. The 2nd All Africa Postharvest Congress and Exhibition, Addis Ababa, 17-20 September 2019.

[19] Rajak, M. and Shaw, K. (2019) Technology in Society Evaluation and Selection of Mobile Health (mHealth) Applications Using AHP and Fuzzy TOPSIS. Technology in Society, 59, Article ID: 101186. https://doi.org/10.1016/j.techsoc.2019.101186

[20] Vijayan, S., Arjunan, T.V. and Kumar, A. (2016) Mathematical Modeling and Performance Analysis of Thin Layer Drying of Bitter Gourd in Sensible Storage Based 
Indirect Solar Dryer. Innovative Food Science and Emerging Technologies, 36, 59-67. https://doi.org/10.1016/j.ifset.2016.05.014

[21] Ouafi, N., Benaouda, N., Moghrani, H., Yassaa, N. and Maachi, R. (2016) Experimental Analysis of Solar Drying Kinetic of Algerian Bay Leaves (Laurus nobilis L.). Revue des Renouvelables, 19, 251-264.

[22] Wang, W., Li, M., Hassanien, R.H.E., Wang, Y. and Yang, L. (2018) Thermal Performance of Indirect Forced Convection Solar Dryer and Kinetics Analysis of Mango. Applied Thermal Engineering, 134, 310-321.

https://doi.org/10.1016/j.applthermaleng.2018.01.115

[23] Barati, A.A., Azadi, H., Pour, M.D., Lebailly, P. and Qafori, M. (2019) Determining Key Agricultural Strategic Factors Using AHP-MICMAC. Multidisciplinary Digital Publishing Institute, Basel. https://doi.org/10.3390/su11143947

[24] Chinenye, N.M. (2009) Effect of Drying Temperature and Drying Air Velocity on the Drying Rate and Drying Constant of Cocoa Bean. Agricultural Engineering International: The CIGRE Journal, 11, 1.

[25] Romuli, S., Nagle, M., Chege, C.G.K. and Müller, J. (2019) Technical Performance of an Inflatable Solar Dryer for Drying Amaranth Leaves in Kenya. Multidisciplinary Digital Publishing Institute, Basel, 9. https://doi.org/10.3390/app9163431

[26] Karthikeyan, A.K. and Murugavelh, S. (2018) Thin Layer Drying Kinetics and Exergy Analysis of Turmeric (Curcuma longa) in a Mixed Mode Forced Convection Solar Tunnel Dryer. Journal of Renewable Energy, 128, 305-312.

https://doi.org/10.1016/j.renene.2018.05.061 